\title{
Case Report: Successful Surgical and Medical Management of Primary Intracranial Hydatid Cyst
}

\author{
Dr. Manmeet Pal Kaur MBBS ${ }^{1 *}$, Dr. Niten K Garg ${ }^{2}$, Dr. Kanika Kinra MBBS ${ }^{3}$, Dr. Venus Sharma MBBS ${ }^{4}$
}

${ }^{1}$ Punjab Institute of Medical Sciences Jalandhar, Punjab, India

${ }^{2}$ DNB Neurosurgery S.G.L. Superspeciality Hospital Garha Road Jalandhar, Punjab, India

${ }^{3}$ 3rdYear Resident Internal Medicine S.G.L. Superspeciality Hospital Garha Road Jalandhar, Punjab, India

${ }^{4}$ Punjab Institute of Medical Sciences Jalandhar, Punjab, India

Hydatid cyst is caused by the infestation of the larvae of taenia echinococcus. They are mostly found in liver or lungs [1]. Brain infestation occurs in $1-2 \%$ cases of echinococcus infection. Isolated hydatid cyst in brain is rare presentation [2, 3]. Cysts may drain into ventricles or rupture completely, causing spillage of contents into the subarachnoid space, leading to fatal anaphylactic shock, meningitis or local recurrence .we are presenting a case of left temporal lobe isolated hydatid cyst in 65 year old lady with exclusive presentation and operated in time showed wonderful outcome.

Keywords: Surgical medical management intracranial.

Copyright @ 2020: This is an open-access article distributed under the terms of the Creative Commons Attribution license which permits unrestricted use, distribution, and reproduction in any medium for non-commercial use (NonCommercial, or CC-BY-NC) provided the original author and source are credited.

\section{INTRODUCTION}

Hydatid cyst is caused by the infstation of the larvae of taenia echinococcus. The definitive hosts of echinococcus are various carnivores, the common being the dog. All mammals are intemittent hosts. Humans get infected with feco-oral route by ingestion of food contaminated by dog feces containing ova of the parasite or by direct contact with dogs.

Hydatid cysts are more prevalent in china, india, the middle east and mediterranean countries, australia, new zealand, south america, russia, france [4$6]$. They are most commonly (about 50-75\%) seen in children and young adults $[7,8]$. The liver is the most common organ involved $(77 \%)$, followed by the lungs $(43 \%)$ [9-12]. Hydatid cysts have been reported in the brain $(2 \%)$ [13].

Cysts may drain into ventricles or rupture completely, causing spillage of contents into the subarachnoid space, leading to fatal anaphylactic shock, meningitis or local recurrence [14]. Surgery is the mainstay for treating intracranial hydatid cysts and the aim is to excise the cysts entirely without rupture, which can otherwise lead to catastrophic events such as anaphylaxis [14].

\section{CASe History}

$65 \mathrm{yr}$ old lady presented with history of headache for last 3 months, seizures for last 1 month, disorientation for last 7 days. On physical examination, patient was confused and disoriented with bilateral papillodema and right hemiparesis. $\mathrm{Ct}$ scan head and mri brain revealed large left temporal lobe cystic lesion $[15,16]$. Lesion was excised by left fronto-temporal craniotomy. Cyst was decompressed first with needle aspiration followed by complete excision with irrigation with warm saline between brain and cyst wall. Pathological examination confirmed it as hydatid cyst. X-ray chest and usg of abdomen failed to show any lung or liver infestation. Post-operatively, albendazole $15 \mathrm{mg} / \mathrm{kg}$ was started and continued for four weeks. The patient showed marked improvement in her neurological deficit and was discharged after one week with close follow-up.1 year after surgery, she remained well and free of disease. We recommend that for treating brain hydatid cyst, the size of the cyst, multiplicity, location and neurological deficit must all be taken into consideration. 

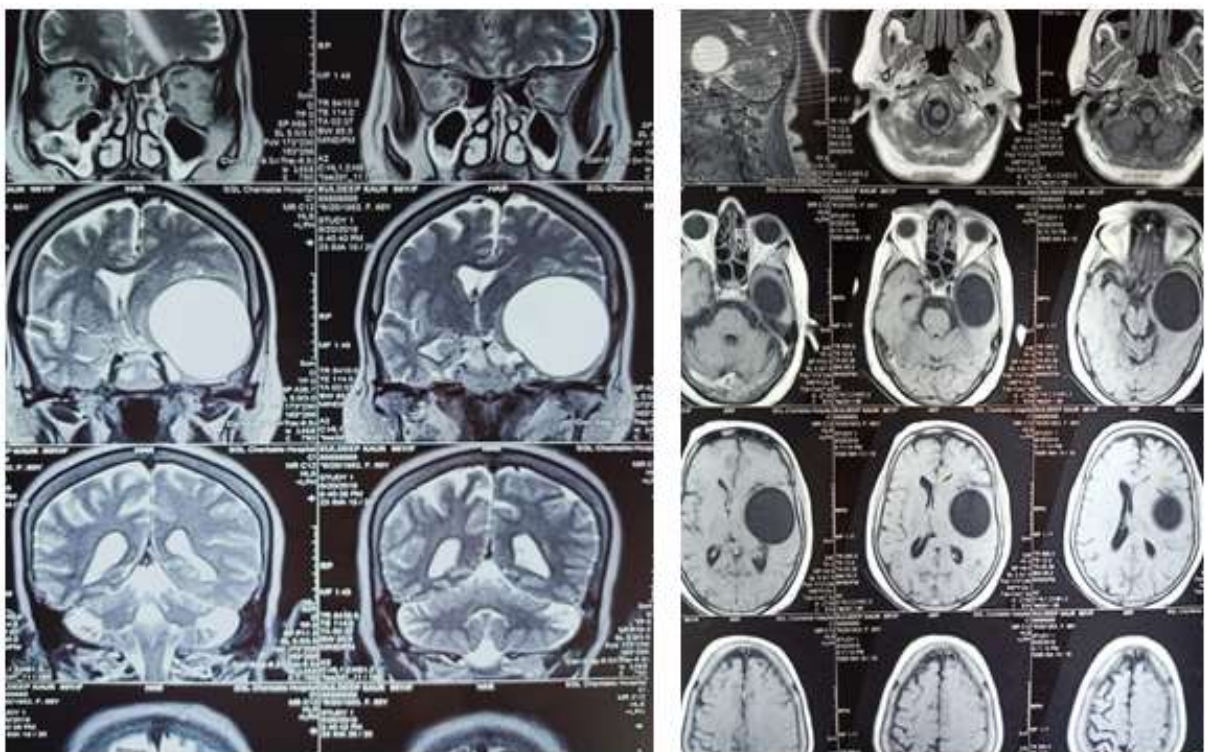

Fig-1,2 \& 3: Mri and Ct Scan Showing Left Temporal Lobe Cystic Lesion
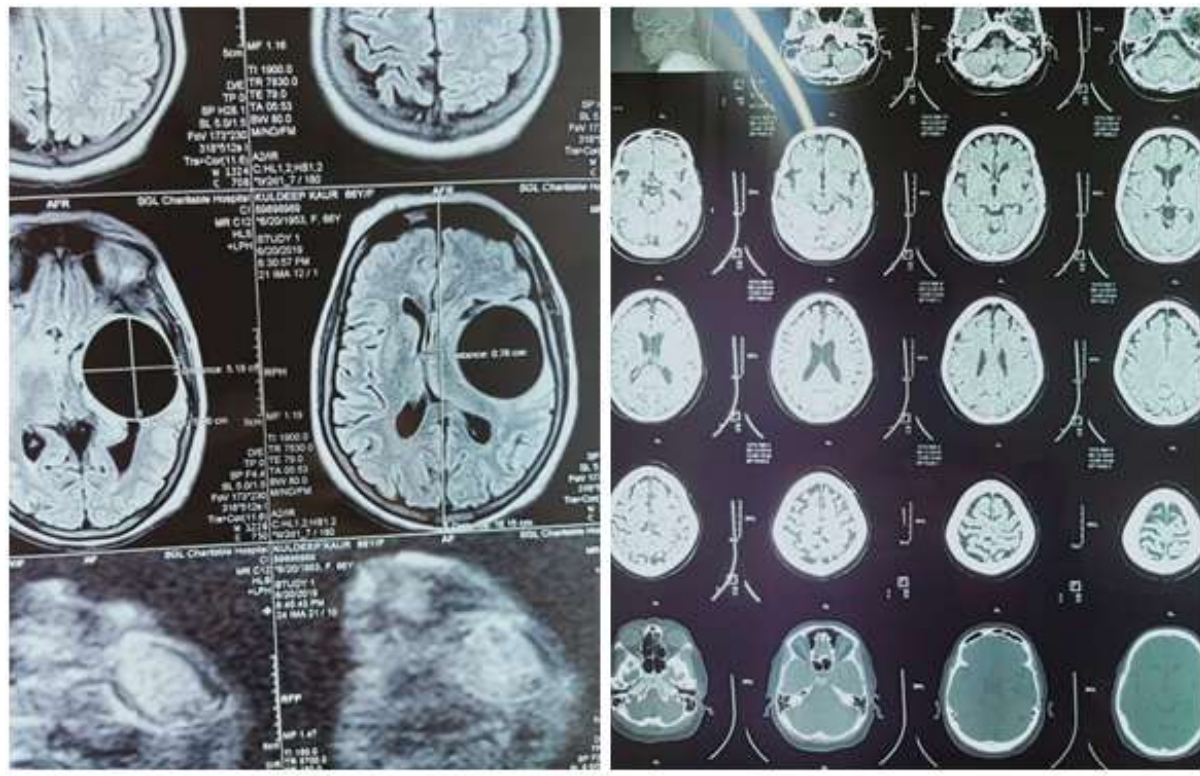

Fig-4: CT scan after excision of the cyst

\section{DiSCUSSION}

Intracranial hydatid cysts are classified as primary or secondary. Primary cysts are formed as aresult of direct infestation of thelarvae in the brain without demonstrable involvement of other organs.some factors which may lead to primary cerebral hydatid disease can be lack of effective immune system in the brain, special architecture of brain tissue, patent ductus arteriosus and patent foramen ovale [17]. In our single case, 2d-echocardiography was normal. In primary multiple cysts, each cyst has a separate pericyst with brood capsule scolices and these originate from multiple larvae affecting brain after crossing the gastrointestinal tract, liver, lungs and right side of heart without affecting them. The primary cysts are fertile as they contain scolices and brood capsules, hence rupture of primary cyst can result in recurrence. The secondary multiple cysts results from spontaneous, traumatic or surgical rupture of the primary intracranial hydatid cyst and they lack brood capsule and scolices. The secondary intracranial hydatid cysts are therefore, infertile and the resultant risk of recurrence after their rupture is negligible.

Magnetic resonance and ct scans characteristically show a spherical, well defined, nonenhancing cystic lesion without peripheral edema. The treatment of hydatid cyst is surgical. The aim of the surgery is to excise the cyst in toto without ruputure to prevent recurrence and anaphylactic reaction. Dowlingorlando technique remains the preffered method, in which the cyst can be delivered by lowering the head of the operating table and installing warm saline between cyst and the surrounding brain parenchyma. This is possible because of minimal adhsions around the cyst wall [18]. 
Some isolated case reports have shown complete disappearance of multiple intracranial hydatid cysts with albendazole therapy in a daily dose of $10 \mathrm{mg} / \mathrm{kg}$,taken three times a day for 4 months $[19,20]$.

\section{Conclusion}

Incidence of primary hydatid cyst of brain is very rare. Patent ductus arteriosus and patent foramen ovale have been the proposed factors. In our case, larvae might have passed through the capillary filter of the liver and lungs, entered into the sytemic circulation and reached the brain. Sometimes because of large size, in toto removal or medical management is not possible, in that case intracystic decompression followed by removal of the cyst wall by gentle traction and saline irrigation between cyst wall brain interfaces is a better option followed by oral anti helminthic drugs.

\section{REFERENCES}

1. Kizilca O, Altas M, Senol U, Oztek MA. Hydatid disease located in the cerebellomedullary cistern. Case Rep Med. 2014;2014:271365.

2. Altinors N, Bavbek M, Caner HH, Erdogan B. Central nervous system hydatidosis in Turkey: A cooperative study and literature survey analysis of 458 cases. J Neurosurg. 2000; 93(1):1-8.

3. Rurnana M, Mahadevan A, Khurshid MN, Kovoor JM, Yasha TC, Santosh V, Indira B, Shankar SK. Cestode parasitic infestation: intracranial and spinal hydatid disease--a clinicopathological study of 29 cases from South India. Clinical neuropathology. 2006 Mar 1; 25(2).

4. Reddy Dr. managing cerebral and cranial hydatid disease. Neurol india. 2009; 57:116-118.

5. Kovoor jme, thomas rd, chandrashekhar hs, jayakumar pn, pillai s, shankar sk. Neurohydatidosis. Australas radiol. 2007; 51:406411.

6. Ersahin $\mathrm{Y}$, mutluer $\mathrm{S}$, güzelbag $\mathrm{E}$. Intracranial hydatid cysts in children. Neurosurgery. 1993; 33(2): 219-224.

7. Cavusoglu H, Tuncer C, Ozdilmaç A, Aydin Y. Multiple Intracranial Hydatid cysts in a boy. Turk Neurosurg. 2009; 19(2):203-207.
8. Sierra J, Oviedo J, Berthier M, Leiguardo R. Growth rate of secondary hydatid cysts of the brain. Case report. J Neurosurg. 1985; 62:781-782.

9. Gana R, Skhissi M, Maaqili R, Bellakhdar F. Multiple infected cerebral hydatid cysts. J Clin Neurosci 2008;15(5):591-593.

10. Andronikou S, Welman C, Kader E. Classic and unusual appearances of hydatid disease in children. Pediatr Radiol. 2002;32: 817-828

11. Afsar H, Yagci N, Aybasti N. Hydatid disease of the kidney. Br J Urol. 1994;73:17-22

12. Dahniya MH, Hanna RM, Ashebu S. The imaging appearances of hydatid disease at some unusual sites. Br J Radiol. 2001; 74:283-289.

13. Kayaoglu CR. Giant hydatid cyst in the posterior fossa of a child: a case report. J Int Med Res. 2008; 36(1)198-202. Khaldi M, Mohamed S, Kallel J, Khouja N. Brain hydatidosis: report on 117 cases. Childs Nerv Syst. 2000; 16:765-769.

14. Lunardi P, Missori P, Di Lorenzo N, Fortuna A. Cerebral hydatidosis in childhood: a retrospective survey with emphasis on long-term follow-up. Neurosurgery. 1991 Oct 1;29(4):515-8.

15. Coates R, von Sinner W, Rahm B. MR imaging of an intracerebral hydatid cyst. AJNR Am J Neuroradiol. 1990; 11:1249-50.

16. Karak PK, Mittal M, Bhatia S, Mukhopadhyay S, Berry M. Isolated cerebral hydatid cyst with pathognomonic CT sign. Neuroradiology. 1992; 34:9-10. [PubMed] [Google Scholar

17. Arana Iniguez R. Echinococcus. Infection of the nervous system. In: Vinken PJ, Bruyn GW, editors. Hand Book of Clinical Neurology, Part III. Amsterdam: Elsevier/North Holland Biomedical Press; 1978: 175-208.

18. Singounas EG, Leventis AS, Sakas DE, Hadley DM, Lampadarios DA, Karvounis PC. Successful treatment of intracerebral hydatid cysts with albendazole: Case report and review of the literature. Neurosurgery. 1992; 31:571-4.

19. Todorov T, Vutova K, Petkov D, Balkanski G. Albendazole treatment of multiple cerebral hydatid cysts: Case report. Trans R Soc Trop Med Hyg. 1988; 82:150-2. 